\title{
Solidified Floating Organic Drop Microextraction for the Detection of Trace Amount of Lead in Various Samples by Electrothermal Atomic Absorption Spectrometry
}

\author{
Oya Aydın Urucu, Şeyda Dönmez, and Ece Kök Yetimoğlu \\ Department of Chemistry, Marmara University, Göztepe, 34722 Istanbul, Turkey \\ Correspondence should be addressed to Oya Aydın Urucu; oaydinurucu@gmail.com
}

Received 24 April 2017; Accepted 15 June 2017; Published 20 July 2017

Academic Editor: Miguel de la Guardia

Copyright (C) 2017 Oya Aydın Urucu et al. This is an open access article distributed under the Creative Commons Attribution License, which permits unrestricted use, distribution, and reproduction in any medium, provided the original work is properly cited.

\begin{abstract}
A novel method was developed for determination of trace amounts of lead in water and food samples. Solidified floating organic drop microextraction was used to preconcentrate the lead ion. After the analyte was complexed with 1-(2-pyridylazo)-2-naphthol, undecanol and acetonitrile were added as extraction and dispersive solvent, respectively. Variables such as $\mathrm{pH}$, volumes of extraction and dispersive solvents, and concentration of chelating agent were optimized. Under the optimum conditions, the detection limit of $\mathrm{Pb}$ (II) was determined as $0.042 \mu \mathrm{g} \mathrm{L}{ }^{-1}$ with an enrichment factor of 300 . The relative standard deviation is $<10 \%$. Accuracy of the developed procedure was evaluated by the analysis of certified reference material of human hair (NCS DC 73347) and wastewater (SPS-WW2) with satisfactory results. The developed procedure was then successfully applied to biscuit and water samples for detection of $\mathrm{Pb}$ (II) ions.
\end{abstract}

\section{Introduction}

Lead is an important naturally occurring heavy metal. It is found in small amounts in the earth's crust and is used in many areas including industrial, agricultural, and domestic areas $[1,2]$. Lead is used in many industrial processes such as metal products, lead-acid batteries, manufacturing of lead based paints, and automobile exhaust accumulators, ammunitions, and so on. Humans can be exposed to lead by air, water, or food contamination. This creates serious health risks for both humans and animals. Lead accumulates in soft tissues in young and middle-aged people and in bones in older people. The accumulation of lead in the kidneys and liver is also quite high $[1,3]$. In the liver, tetramethyl lead turns into a much more toxic triethyl lead and causes the increase in the amount of lead in the urine. The World Health Organization (WHO) recommended a limit of $10 \mu \mathrm{gL}^{-1}$ of lead in potable water [4] and according to International/National Standards, maximum permitted concentration of lead in all food in solid form is $6 \mu \mathrm{gL}^{-1}$.
The detection of heavy metals in various samples is important for human health. The most commonly used instrumental methods are flame atomic absorption spectrometry (FAAS), electrothermal atomic absorption spectrometry (ETAAS), inductively coupled plasma optical emission spectrometry (ICP-OES), and inductively coupled plasma-mass spectrometry (ICP-MS) [5]. Direct detection of trace amounts of heavy metal ions in real samples by AAS is difficult due to matrix effects and a low detection limit is difficult [6]. The easiest way to deal with this difficulty is to use separation-preconcentration method before analysis. In recent years, a number of easily applicable separationpreconcentration methods have been developed. These methods require the use of a small amount of organic solution. The most commonly used methods are single drop microextraction (SDME) [7, 8], coprecipitation [9], solid phase microextraction (SPME) [10, 11], cloud point extraction (CPE) [12], dispersive liquid-liquid microextraction (DLLME) [13, 14], and solidified floating organic drop microextraction (SFODME) $[15,16]$. 


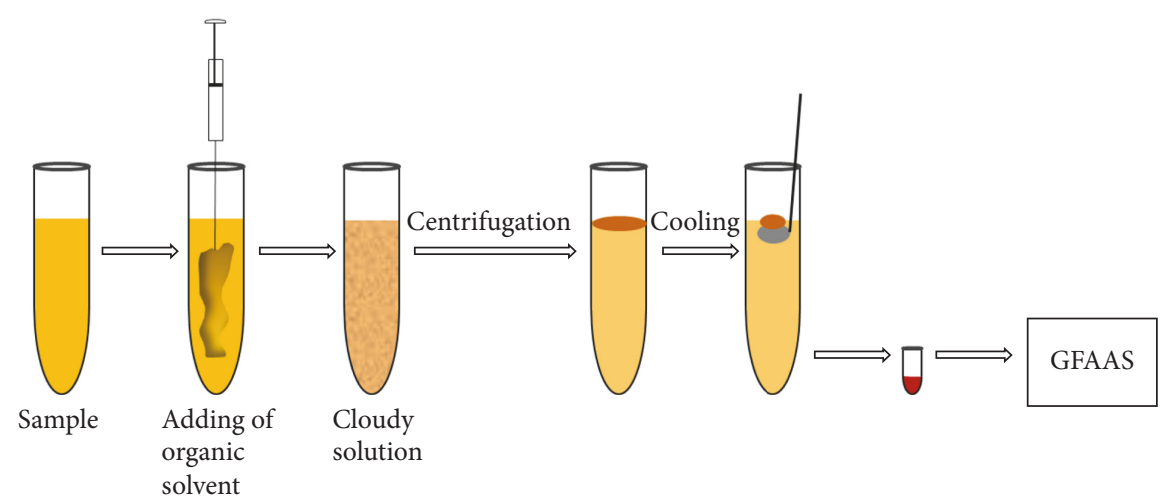

FIGURE 1: Schematic diagram of DLLME-SFO method.

TABLE 1: The temperature program of graphite furnace atomizer.

\begin{tabular}{lccccc}
\hline Step & Start $T\left({ }^{\circ} \mathrm{C}\right)$ & End $T\left({ }^{\circ} \mathrm{C}\right)$ & Ramp time $(\mathrm{s})$ & Hold time $(\mathrm{s})$ & ${\text { Ar flow rate }\left(\mathrm{mL} \mathrm{min}{ }^{-1}\right)}$ \\
\hline Drying & 80 & 140 & 40 & 2 & 2 \\
Ashing & 500 & 1400 & 20 & 5 & 250 \\
Atomizing & 1400 & 2200 & 0 & 4 & 0 \\
Clean & 2200 & 0 & 50 & 250 \\
\hline
\end{tabular}

The most important feature of the SFODME method is that the analyte in the aqueous sample is trapped in a small drop of the extract solution. The density of organic solvents used in this method is less than the density of water. In SFODME method, a mixture of dispersive and extraction solvents is quickly injected into aqueous sample by microsyringe and the solution becomes cloudy. Then the extraction solution is separated by centrifuging the cloudy solution. The test tube is placed in the ice bath for the freezing of the organic phase. Then the extraction solution is collected in another test tube using a spatula. The organic droplet melts at room temperature and is dissolved in a suitable solvent before analysis is ready. A schematic diagram of SFODME is shown in Figure 1. This method is a widely accepted, optimal, and powerful technique because of its use of negligible volumes of solvents, high enrichment factor, low cost, low consumption of organic solvents, simplicity of automation, ability to detect analytes at very low concentrations, and the ability to be coupled with various modern detection techniques [24, 25].

In this study, we selected 1-(2-pyridylazo)-2-naphthol (PAN), which is the classical organic reagent for spectrophotometric determination of transition metal ions as a chelating reagent. We have developed a new SFOMDE method combined with GFAAS for detection and separation of lead in various samples. We have optimized the factors affecting the extraction efficiency such as $\mathrm{pH}$, sample volume, ionic strength, concentration of organic ligands, and solvent volume.

\section{Experimental}

2.1. Instrumentation. An AAS ZEEnit 700P atomic absorption spectrometer (Analytik Jena AG, Jena, Germany) with deuterium background correction, equipped with a transversely heated graphite tube atomizer, was used for all measurements. The temperature program for the ETAAS is shown in Table 1. The lead hollow cathode lamp (Analytik Jena AG, Konrad, Zuse, Germany) was operated at $4.0 \mathrm{~mA}$ and the analytical line at $283.3 \mathrm{~nm}$ was used with a spectral bandwidth of $0.5 \mathrm{~nm}$. Mettler Toledo $\mathrm{pH}$ meter was used to measure the $\mathrm{pH}$. An analytical Precisa XB 220A balance was used for all weights measurements and Hettich EBA 21 model centrifuge was used for centrifugation. A CEM MARS microwave digestion system was used for ore sample digestion.

2.2. Reagents and Standard Solutions. In this study, the reagents of the highest purity and analytical grade were used. The standard stock solution of $\mathrm{Pb}$ (II) $\left(1000 \mathrm{mgL}^{-1}\right)$ was prepared by dissolving $1,599 \mathrm{~g}$ of $\mathrm{Pb}\left(\mathrm{NO}_{3}\right)_{2}$ (Merck) in $1000 \mathrm{~mL}$ of $0.5 \%$ nitric acid solution. The working solutions of the $\mathrm{Pb}(\mathrm{II})$ ions were prepared by suitable dilution from stock solution using deionised water. 1-Undecanol was used as an extracting solvent (Merck), while acetonitrile was used as dispersive solvent.

1-(2-Pyridylazo)-2-naphthol (PAN) solution was prepared by dissolving $0.01246 \mathrm{~g}$ of PAN (Sigma-Aldrich) in of $50 \mathrm{ml}$ of ethanol. $\mathrm{NH}_{3} / \mathrm{NH}_{4} \mathrm{Cl}$ buffer solutions were prepared by mixing appropriate amounts of $1.0 \mathrm{~mol} \mathrm{~L}^{-1} \mathrm{NH}_{3}$ (Merck) and $1.0 \mathrm{~mol} \mathrm{~L}^{-1} \mathrm{NH}_{4} \mathrm{Cl}$ (Merck) solutions for $\mathrm{pH}$ values from 8 to 10.5 .

2.3. Microwave Digestion of Certified Reference Material (CRM). 50 mg CRM (NCS DC 73347) weights were transferred into the microwave vessels and then $6 \mathrm{~mL} \mathrm{HNO}_{3}(65 \%$ $\mathrm{w} / \mathrm{v}), 3 \mathrm{~mL} \mathrm{H} \mathrm{O}_{2}(30 \% \mathrm{w} / \mathrm{v})$, and $1 \mathrm{~mL} \mathrm{HF}$ were added. Optimized microwave program $\left(180^{\circ} \mathrm{C}\right.$ for $\left.20 \mathrm{~min}\right)$ was applied. 
This vessel was cooled to room temperature and then the volume was brought up to $25 \mathrm{~mL}$ with distilled water.

2.4. General Procedure. Aliquots of $10 \mathrm{~mL}$ standard solution containing $10 \mu \mathrm{gL}^{-1} \mathrm{~Pb}$ were placed in a $15 \mathrm{~mL}$ conical centrifuge tube. The $\mathrm{pH}$ was adjusted to 9 with a $\mathrm{NH}_{3} / \mathrm{NH}_{4} \mathrm{Cl}$ buffer, while ionic strength was set to $20 \%$ by using $\mathrm{NaCl}$. The amount of $1 \mathrm{ml}$ PAN $\left(1 \times 10^{-4} \mathrm{~mol} \mathrm{~L}^{-1}\right), 100 \mu \mathrm{L}$ 1-undecanol (extraction solvent), and $200 \mu \mathrm{L}$ acetonitrile (dispersive solvent) was quickly injected into the sample solution by using a syringe. A cloudy mixture was formed in the sample tube indicating that $\mathrm{Pb}$ reacted with PAN. The mixture was centrifuged for $15 \mathrm{~min}$ at $5000 \mathrm{rpm}$, allowing the separation of the organic phase at the top of the tube. After cooling the sample tube in an ice bath, the organic phase was transferred into another tube and diluted to $500 \mu \mathrm{L}$ with ethanol. The solution was then analyzed by using the GFAAS.

\section{Result and Discussion}

The effects of different experimental parameters such as the extraction time, concentration of chelating agent and complex with standard solution, buffer solution selection, $\mathrm{pH}$, extraction volume, dispersive solvent, salt addition, and sample volume were investigated to obtain the optimum SFODME conditions.

3.1. Effect of Type and Volume of Extraction Solvent. The selection of a correct extraction solvent is crucial for optimization of the SFODME process. Extraction solvent must have low volatility, solubility, and toxicity, be stable for the duration of extraction, extract required analytes well, and have a melting point close to the room temperature. Based on this information, we tested two different organic extraction solvents such as 1-undecanol and 1-dodecanol. The experimental results demonstrated that the best extraction of the target analyte was achieved when 1-undecanol was used as the extraction solvent. Hence, solutions including different volumes of 1-undecanol $(50-175 \mu \mathrm{l})$ were applied to the same SFODME procedure to investigate the effect of solvent volume on extraction. The results are shown in Figure 2.

According to the results, the extraction recovery increased with the increased volume of the extraction solvent; however, the recovery was maximum when volumes of more than $100 \mu \mathrm{l}$ were used. Therefore, $100 \mu \mathrm{l}$ of 1 undecanol was decided as the optimum volume of extraction solvent to achieve good sensitivity and high enrichment.

3.2. Effect of Type and Volume of Dispersive Solvent. In order to be successfully used in SFODME, the selected dispersive solvent must be miscible with both water and extraction solvents. A cloudy solution should be obtained when dispersive solvent is injected together with the extraction solvent and ligand into aqueous mixture. Dispersive solvent must have a low cost, low toxicity, and low volatility. Various dispersive solvents such as methanol, acetone, ethanol, and acetonitrile were tested. The recovery was the highest with acetonitrile; therefore, acetonitrile was selected as dispersive solvent. Subsequently, the volume of acetonitrile was optimized by

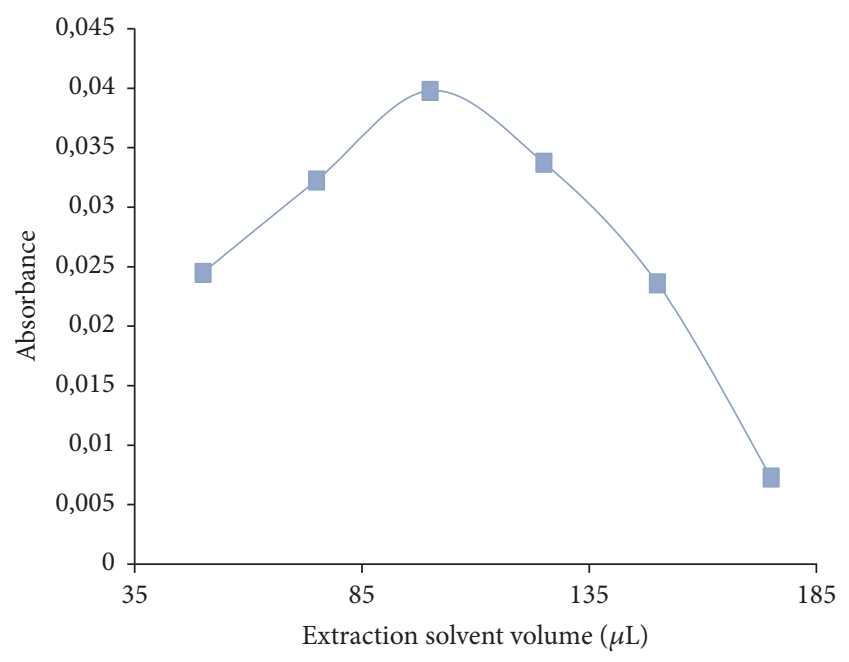

FIGURE 2: The effect of the extraction solvent volume on absorbance of lead with SFODME. Extraction circumstances: $\mathrm{Pb}: 10 \mu \mathrm{gL}^{-1}$; pH: 9; extraction solvent, 1-undecanol $(100 \mu \mathrm{L})$; sample volume, $10 \mathrm{~mL}$; dispersive solvent, acetonitrile $(200 \mu \mathrm{L}) ; \% 1.6 \mathrm{NaCl}$; chelating reagent $[\mathrm{PAN}], 1 \times 10^{-4} \mathrm{~mol} \mathrm{~L}^{-1}$.

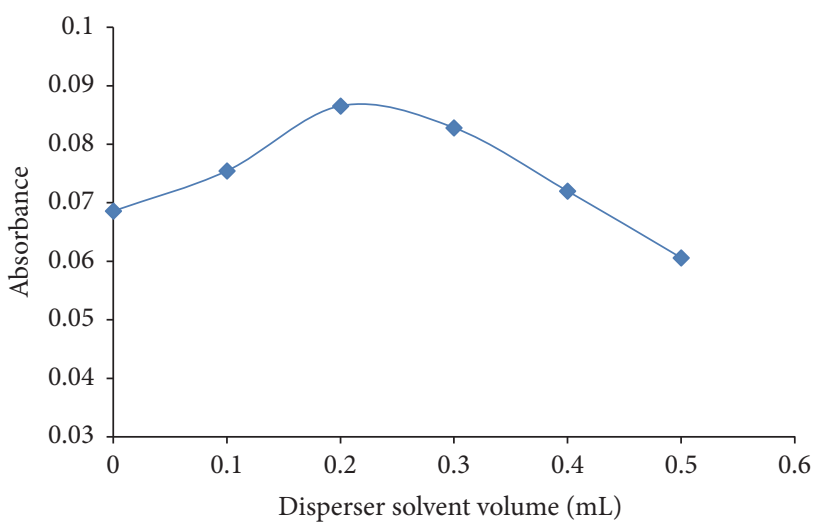

FIgURE 3: The effect of dispersive solvent volume on absorbance of lead for SFODME. Extraction circumstances: $\mathrm{Pb}: 10 \mu \mathrm{gL} \mathrm{L}^{-1}$; $\mathrm{pH}$ : 9; extraction solvent, 1-undecanol $(100 \mu \mathrm{L})$; sample volume, $10 \mathrm{~mL} ; \mathrm{pH}$ : 9; \% $1.6 \mathrm{NaCl}$ chelating reagent $[\mathrm{PAN}], 1 \times 10^{-4} \mathrm{~mol} \mathrm{~L}^{-1}$.

testing the $100-500 \mu \mathrm{L}$ range in terms of the extraction efficiency (the volume of 1-undecanol as extraction solvent was added at $100 \mu \mathrm{L}$ ). As shown in Figure 3, the extraction efficiency increased with increasing volume of acetonitrile. The highest recovery was obtained with $200 \mu \mathrm{L}$. Hence, $200 \mu \mathrm{L}$ was selected as the optimum volume of the dispersive solvent.

3.3. Effect of Sample Solution pH. $\mathrm{pH}$ is one of the main parameters necessary for the ligand-metal complex reaction. $\mathrm{pH}$ between 9.0 and 10.0 is favorable for complexation of lead and PAN [26]. Therefore, the effect of $\mathrm{pH}$ on the SFODME extraction of lead was investigated in the $\mathrm{pH}$ range of $8-10.5$ by using $\mathrm{NH}_{3} / \mathrm{NH}_{4} \mathrm{Cl}$ buffer solution, while keeping all other factors constant. As shown in Figure 4, the extraction recovery was almost constant at $\mathrm{pH}$ bigger than 9 . Therefore, $\mathrm{pH} 9$ that was adjusted with $\mathrm{NH}_{3} / \mathrm{NH}_{4} \mathrm{Cl}$ buffer solution was 


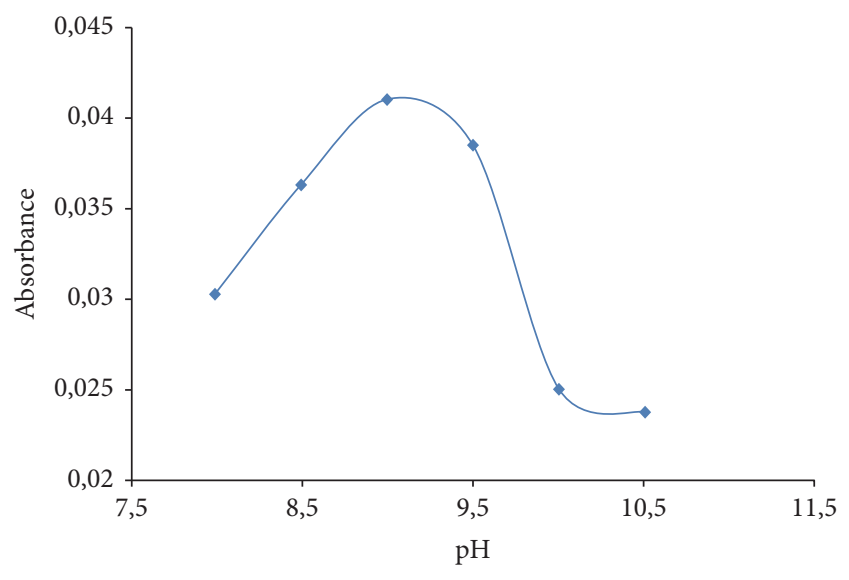

Figure 4: The effect of $\mathrm{pH}$ on the extraction of lead with SFODME. Extraction circumstances: $\mathrm{Pb}: 10 \mu \mathrm{gL} \mathrm{L}^{-1}$; extraction solvent, 1-undecanol $(100 \mu \mathrm{L})$; sample volume, $10 \mathrm{~mL}$; dispersive solvent, acetonitrile $(200 \mu \mathrm{L}) ; \% 1.6 \mathrm{NaCl}$; chelating reagent [PAN], 1 $\times 10^{-4} \mathrm{~mol} \mathrm{~L}^{-1}$.

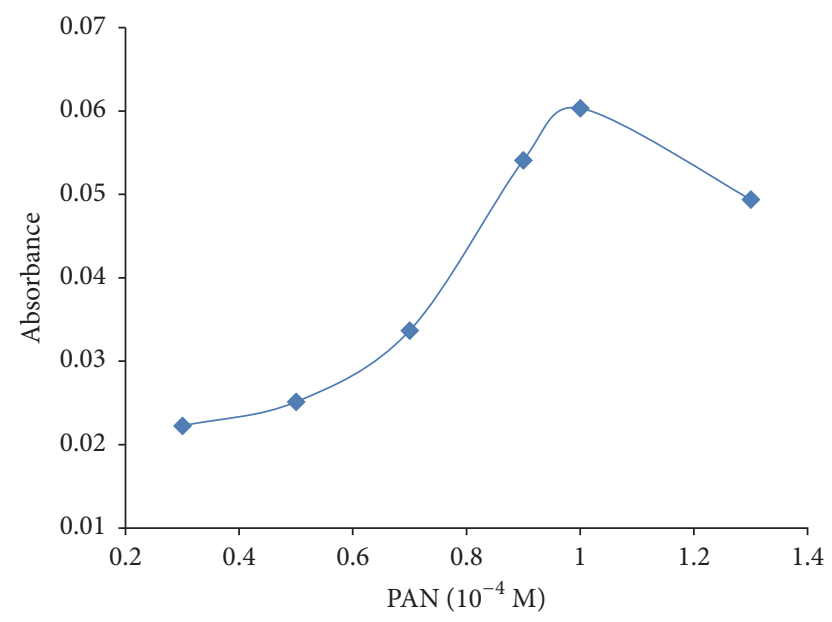

FIGURE 5: The effect of 1-(2-pyridylazo)-2-naphthol concentration on absorbance of lead with SFODME. Extraction circumstances: $\mathrm{Pb}$ : $10 \mu \mathrm{gL}^{-1}$; pH: 9; extraction solvent, 1-undecanol $(100 \mu \mathrm{L})$; sample volume, $10 \mathrm{~mL}$; dispersive solvent, acetonitrile $(200 \mu \mathrm{L})$; chelating reagent $[\mathrm{PAN}], 1 \times 10^{-4} \mathrm{~mol} \mathrm{~L}^{-1}$.

accepted as the optimum $\mathrm{pH}$ value and all subsequent sample analyses were done at $\mathrm{pH} 9$.

3.4. Effect of the Concentration of 1-(2-Pyridylazo)-2-naphthol. 1-(2-Pyridylazo)-2-naphthol (PAN) is a classical spectrometric reagent used for analysis of metal ions. The metal chelates of PAN have the metal atom bonded to $\mathrm{O}$ of the $\mathrm{OH}$ group, to pyridine $\mathrm{N}$, and to azo $\mathrm{N}$ [27]. In this study, PAN formed a strong complex with the $\mathrm{Pb}$ ions at $\mathrm{pH}$ 9. The effects of various PAN concentrations ranging from $0.2 \times 10^{-4}$ to $1.4 \times$ $10^{-4} \mathrm{~mol} \mathrm{~L}^{-1}$ on extraction efficiency were investigated. The results are demonstrated in Figure 5.

According to these results, increasing concentrations of PAN resulted in higher recovery but it was stable at
TABLE 2: Effect of the coexisting ions on the recoveries of the $\mathrm{Pb}$ (II).

\begin{tabular}{lc}
\hline Coexisting ions & Molar ratio $\left(\right.$ ion $\left./ \mathrm{Pb}^{+2}\right)$ \\
\hline $\mathrm{Ba}^{+2}$ & 2000 \\
$\mathrm{~K}^{+}$ & 2000 \\
$\mathrm{Cd}^{+2}$ & 2000 \\
$\mathrm{Ni}^{+2}$ & 800 \\
$\mathrm{Cu}^{+2}$ & 800 \\
$\mathrm{Ag}^{+}$ & 200 \\
$\mathrm{Zn}^{+2}$ & 200 \\
$\mathrm{Mg}^{+2}$ & 200 \\
$\mathrm{Hg}^{+2}$ & 200 \\
$\mathrm{Co}^{+2}$ & 200 \\
$\mathrm{Fe}^{+3}$ & 200 \\
\hline
\end{tabular}

$1 \times 10^{-4} \mathrm{~mol} \mathrm{~L}^{-1}$. For this reason, $1 \times 10^{-4} \mathrm{~mol} \mathrm{~L}^{-1}$ was chosen as optimum concentration for this study.

3.5. Effect of Salt Addition. In this study, the effect of ionic strength on the SFODME performance was tested with $\mathrm{NaCl}$ concentration ranging from 0 to $4 \%$, while all other parameters were constant. Salt addition increased the extraction efficiency but the efficiency reached the plateau at $1.6 \% \mathrm{NaCl}$ concentrations. Thus, the optimal salt amount was determined as $1.6 \% \mathrm{NaCl}$.

3.6. Effect of Different Ions. The effect of potential interfering cations was tested in optimal conditions in order to measure the degree of usefulness of newly developed SFODME method in analytical applications. Hence, according to the detected procedure, $10.0 \mathrm{ml}$ of solutions containing $10 \mu \mathrm{gL}^{-1}$ of lead and varied quantity of interfering ions were treated. The results are shown in Table 2. Based on the results shown in Table 2, specified amount of cations have no effect on the quantitative determination of the amount of lead in the sample.

3.7. Effect of Sample Volume. The effects of sample volume on the recovery of $\mathrm{Pb}$ (II) ions were investigated with volumes ranging from $10 \mathrm{~mL}$ to $100 \mathrm{~mL}$ by using model solutions prepared at the optimal conditions. Quantitative recovery was obtained for every volume. The preconcentration factor for $\mathrm{Pb}$ (II) calculated by taking the ratio of the highest sample volume $(100 \mathrm{~mL})$ and the lowest final volume $(0,3)$ was 333 , while the enhancement factor, which is the ratio of the slope of calibration curve of the analytes after preconcentration to that prior to the preconcentration, was 300 .

3.8. Analytical Performance of the Procedure. The linear range of SFODME procedure was calculated by analyzing different $\mathrm{Pb}$ (II) ion concentrations. The linear dynamic range was determined as $0.05-40 \mu \mathrm{gL}^{-1}$ with the correlation coefficient $\left(R^{2}\right)$ exceeding 0.9986 . The detection limit, which is defined as the concentration equivalent to three times the standard deviation $(N=10)$ of the reagent blank, was $0.042 \mu \mathrm{gL}^{-1}$. The recovery values for the analytes were between 91 and 100 
TABLE 3: Determination of $\mathrm{Pb}(\mathrm{II})$ ions in human hair and biscuit samples.

\begin{tabular}{lccc}
\hline Sample & Certified Pb (II) $\left(\mu \mathrm{g} \mathrm{L}^{-1}\right)$ & Found $\left(\mu \mathrm{g} \mathrm{L}^{-1}\right)$ & Recovery $(\%)$ \\
\hline Hair reference material (NCS DC 73347) & 8,8 & $8,5 \pm 0.02$ & $96.6 \pm 2$ \\
Biscuit & 24 & $24.10 \pm 0.05$ & $100 \pm 1$ \\
Wastewater (SPS-WW2) & 500 & 495 & 99 \\
\hline
\end{tabular}

TABLE 4: Determination of $\mathrm{Pb}$ (II) ions in tap-water and river-water samples.

\begin{tabular}{lccr}
\hline Sample & Added $\left(\mathrm{Pb}^{2+}\right)\left(\mu \mathrm{g} \mathrm{L}^{-1}\right)$ & Found $\left(\mu \mathrm{g} \mathrm{L}^{-1}\right)$ & Recovery $(\%)$ \\
\hline \multirow{3}{*}{ Tap water } & 0 & - & - \\
& 12.5 & $12.32 \pm 0.03$ & $98.56 \pm 2$ \\
& 15 & $14.77 \pm 0.02$ & $98.46 \pm 2$ \\
& 17.5 & $16.0 \pm 0.01$ & $91.42 \pm 1$ \\
River water & 0 & - & - \\
& 12.5 & $11.98 \pm 0.01$ & $95.84 \pm 1$ \\
& 15 & $14.74 \pm 0.02$ & $98.26 \pm 2$ \\
& 17.5 & $16.66 \pm 0.01$ & $95.20 \pm 1$ \\
\hline
\end{tabular}

TABLE 5: Comparison of the SFODM method with some recent studies on separation and preconcentration of $\mathrm{Pb}(\mathrm{II})$ ions reported in the literature.

\begin{tabular}{|c|c|c|c|c|c|}
\hline Technique & Sample & E.F & $\operatorname{LOD}\left(\mu \mathrm{gL}^{-1}\right)$ & Liner range $\left(\mu \mathrm{gL}^{-1}\right)$ & $\mathrm{R}$ \\
\hline CPE-FAAS & Water and food samples & 25 & 3.42 & $500-10000$ & [17] \\
\hline Coprecipitation-FAAS & Water samples & 40 & 9,7 & - & {$[18]$} \\
\hline HF-LPME-ETAAS & Environmental and biological samples & 76 & 0.02 & $0,04-1$ & [19] \\
\hline DLPME-GFAAS & Water and biological samples & 78 & 0.039 & $0.004-0.03$ & {$[2]$} \\
\hline SPE-FAAS & Environmental water and vegetable samples & 125 & 0.61 & $10-600$ & {$[20]$} \\
\hline SM-DLLME-FAAS & Food samples & - & 0.4 & $1-500$ & [21] \\
\hline SPE-FAAS & Water samples & 20 & 5 & $1-12$ & {$[22]$} \\
\hline SFODME-GFAAS & Water and rack samples & 113 & 0,058 & $0,2-10$ & [23] \\
\hline SFODME-GFAAS & Water and food samples & 300 & 0.042 & $0.05-40$ & This study \\
\hline
\end{tabular}

CPE: cloud point extraction; DLPME: dispersive liquid phase microextraction; HF-LPME: hollow fiber based-liquid phase microextraction; SPE: solid phase extraction; SFODME: solidified floating organic drop microextraction; ETAAS: electrothermal atomic absorption spectrometry; GFAAS: graphite furnace atomic absorption spectrometry; FAAS: flame atomic absorption spectrometry; LOD: limit of detection; E.F: enrichment factor; SM: supramolecular microextraction; R: reference.

percent. Meanwhile, the relative standard deviation (RSD\%) was determined to be $<10 \%$.

3.9. Applications of the Presented Method. The proposed SFODME procedure was applied to detect $\mathrm{Pb}$ (II) ion in different samples. Firstly, the accuracy of the method was verified by using NCS DC 73347 (hair reference material) and SPS-WW2 (wastewater), which are certified reference material (Table 3). Prior to the analysis, hair reference material was digested by close microwave. The amount of $\mathrm{Pb}$ (II) ion in tap and river water samples was detected without any pretreatment to the samples (Table 4). The proposed method was also applied to the food samples. The contents of the food sample (biscuit) have also been detected with other methods (Table 3).

\section{Conclusions}

A novel SFODME method was developed for the preconcentration of $\mathrm{Pb}$ (II) ions in hair, food, and water samples. This method is a fast, simple, sensitive, and accurate technique for the preconcentration and detection of $\mathrm{Pb}$ (II). The different ions effect was tolerable. The limit of detection and enrichment factor found in this study were superior to other preconcentration techniques in terms of detection of lead (Table 5). The present method has high enrichment factor and low detection limit; thus, it is suitable for ultratrace analysis of lead in different types of samples. In addition, our method uses very little organic solvent and therefore is environmentfriendly.

\section{Conflicts of Interest}

The authors declare that they have no conflicts of interest.

\section{Acknowledgments}

This work is supported by Marmara University, Scientific Research Commission of Turkey [Project no. FEN-C-YLP140115-0012]. 


\section{References}

[1] P. B. Tchounwou, C. G. Yedjou, A. K. Patlolla, and D. J. Sutton, "Heavy metal toxicity and the environment," Molecular, Clinical and Environmental Toxicology, vol. 101, pp. 133-164, 2012.

[2] Z. A. Alothman, N. H. Al-Shaalan, M. A. Habila, Y. E. Unsal, M. Tuzen, and M. Soylak, "Dispersive liquid-liquid microextraction of lead(II) as 5-(4-dimethylaminobenzylidene) rhodanine chelates from food and water samples," Environmental Monitoring and Assessment, vol. 187, no. 2, 2015.

[3] J. Chen, S. Xiao, X. Wu, K. Fang, and W. Liu, "Determination of lead in water samples by graphite furnace atomic absorption spectrometry after cloud point extraction," Talanta, vol. 67, no. 5, pp. 992-996, 2005.

[4] C. M. George, L. Sima, M. H. Jahuira Arias et al., "Arsenic exposure in drinking water: an unrecognized health threat in Peru," Bulletin of the World Health Organization, vol. 92, no. 8, pp. 565-572, 2014.

[5] Y. A. Zolotov and N. M. Kuzmin, Preconcentration of Trace Elements, Elsevier, 1990.

[6] S. Sadeghi, H. Azhdari, H. Arabi, and A. Z. Moghaddam, "Surface modified magnetic $\mathrm{Fe}_{3} \mathrm{O}_{4}$ nanoparticles as a selective sorbent for solid phase extraction of uranyl ions from water samples," Journal of Hazardous Materials, vol. 215-216, pp. 208-216, 2012.

[7] N. Jalbani and M. Soylak, "Determination of cadmium and lead in water and food by organic drop microextraction and flame atomic absorption spectrometry," Instrumentation Science and Technology, vol. 43, no. 5, pp. 573-587, 2015.

[8] P. Liang, R. Liu, and J. Cao, "Single drop microextraction combined with graphite furnace atomic absorption spectrometry for determination of lead in biological samples," Microchimica Acta, vol. 160, no. 1-2, pp. 135-139, 2008.

[9] Y. Wang, Y. Peng, Y. Chen, K. Du, Y. Li, and X. He, "Sensitive determination of lead by differential pulse anodic stripping voltammetry on silver-based coordination complex modified electrodes," Analytical Methods, vol. 8, no. 8, pp. 1935-1941, 2016.

[10] C. Dietz, J. Sanz, and C. Cámara, "Recent developments in solidphase microextraction coatings and related techniques," Journal of Chromatography A, vol. 1103, no. 2, pp. 183-192, 2006.

[11] A. K. Malik, V. Kaur, and N. Verma, "A review on solid phase microextraction - High performance liquid chromatography as a novel tool for the analysis of toxic metal ions," Talanta, vol. 68, no. 3, pp. 842-849, 2006.

[12] Z. Li, J. Chen, M. Liu, and Y. Yang, "Ultrasound-assisted cloud point extraction coupled with flame atomic absorption spectrometry for the determination of lead and cadmium in water samples," Analytical Methods, vol. 6, no. 10, pp. 3241-3246, 2014.

[13] D. Afzali, A. Ghazizadeh, and H. Salari, "Ion pair-dispersive liquid-liquid microextraction of trace amount of rhodium ion in water and road dust samples prior to flame atomic absorption spectrometry determination," Quimica Nova, vol. 34, no. 7, pp. 1124-1128, 2011.

[14] S. R. Yousefi, F. Shemirani, and M. R. Jamali, "Determination of antimony(III) and total antimony in aqueous samples by electrothermal atomic absorption spectrometry after dispersive liquid-liquid microextraction (DLLME)," Analytical Letters, vol. 43, no. 16, pp. 2563-2571, 2010.
[15] T. Asadollahi, S. Dadfarnia, and A. M. H. Shabani, "Separation/preconcentration and determination of vanadium with dispersive liquid-liquid microextraction based on solidification of floating organic drop (DLLME-SFO) and electrothermal atomic absorption spectrometry," Talanta, vol. 82, no. 1, pp. 208-212, 2010.

[16] M. S. Bidabadi, S. Dadfarnia, and A. M. H. Shabani, "Solidified floating organic drop microextraction (SFODME) for simultaneous separation/preconcentration and determination of cobalt and nickel by graphite furnace atomic absorption spectrometry (GFAAS)," Journal of Hazardous Materials, vol. 166, no. 1, pp. 291-296, 2009.

[17] D. Citak and M. Tuzen, "A novel preconcentration procedure using cloud point extraction for determination of lead, cobalt and copper in water and food samples using flame atomic absorption spectrometry," Food and Chemical Toxicology, vol. 48, no. 5, pp. 1399-1404, 2010.

[18] O. Aydin Urucu and A. Aydin, "Coprecipitation for the Determination of Copper(II), Zinc(II), and Lead(II) in Seawater by Flame Atomic Absorption Spectrometry," Analytical Letters, vol. 48, no. 11, pp. 1767-1776, 2015.

[19] J. Abulhassani, J. L. Manzoori, and M. Amjadi, "Hollow fiber based-liquid phase microextraction using ionic liquid solvent for preconcentration of lead and nickel from environmental and biological samples prior to determination by electrothermal atomic absorption spectrometry," Journal of Hazardous Materials, vol. 176, no. 1-3, pp. 481-486, 2010.

[20] Y. Wang, S. Gao, X. Zang, J. Li, and J. Ma, "Graphene-based solid-phase extraction combined with flame atomic absorption spectrometry for a sensitive determination of trace amounts of lead in environmental water and vegetable samples," Analytica Chimica Acta, vol. 716, pp. 112-118, 2012.

[21] A. Rastegar, A. Alahabadi, A. Esrafili, Z. Rezai, A. HosseiniBandegharaei, and S. Nazari, "Application of supramolecular solvent-based dispersive liquid-liquid microextraction for trace monitoring of lead in food samples," Analytical Methods, vol. 8, no. 27, pp. 5533-5539, 2016.

[22] Ş. Tokalıoğlu, A. Papak, and Ş. Kartal, "Separation/preconcentration of trace $\mathrm{Pb}(\mathrm{II})$ and $\mathrm{Cd}(\mathrm{II})$ with 2-mercaptobenzothiazole impregnated Amberlite XAD-1180 resin and their determination by flame atomic absorption spectrometry," Arabian Journal of Chemistry, vol. 10, no. 1, pp. 19-23, 2017.

[23] M. Chamsaz, J. Akhoundzadeh, and M. H. Arbab-zavar, "Preconcentration of lead using solidification of floating organic drop and its determination by electrothermal atomic absorption spectrometry," Journal of Advanced Research, vol. 4, no. 4, pp. 361-366, 2013.

[24] M. Zuo, J. Cheng, G. Matsadiq, L. Liu, M.-L. Li, and M. Zhang, "Application of Dispersive Liquid-Liquid Microextraction Based on Solidification of Floating Organic Droplet Multiresidue Method for the Simultaneous Determination of Polychlorinated Biphenyls, Organochlorine, and Pyrethroid Pesticides in Aqueous Sample," Clean - Soil, Air, Water, vol. 40, no. 12, pp. 1326-1333, 2012.

[25] G. Peng, Q. He, D. Mmereki et al., "Dispersive solid-phase extraction followed by vortex-assisted dispersive liquid-liquid microextraction based on the solidification of a floating organic droplet for the determination of benzoylurea insecticides in soil and sewage sludge," Journal of Separation Science, vol. 39, no. 7, pp. 1258-1265, 2016. 
[26] Z. Marczenko, Separation and Spectrophotometric Determination of Elements, John Wiely sons, Toronto, Canada, 1986.

[27] Ş. Tokalioǧlu, H. Büyükbaş, and Ş. Kartal, "Preconcentration of trace elements by using 1-(2-pyridylazo)-2-naphthol functionalized amberlite XAD-1180 resin and their determination by FAAS," Journal of the Brazilian Chemical Society, vol. 17, no. 1, pp. 98-106, 2006. 

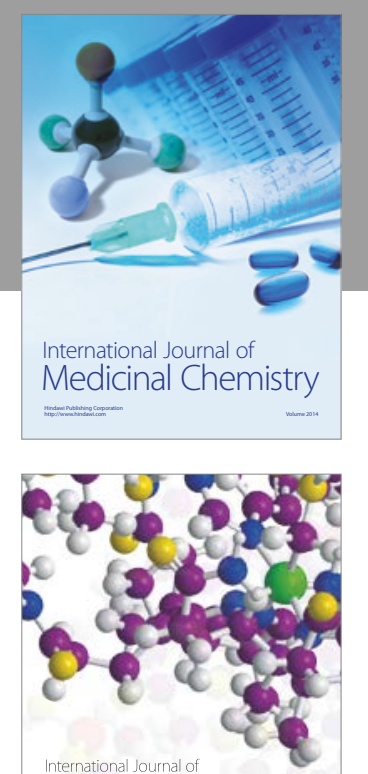

Carbohydrate Chemistry

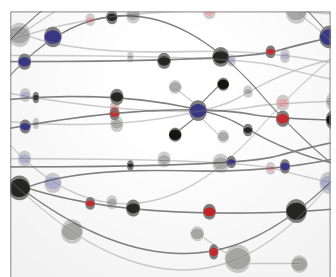

The Scientific World Journal
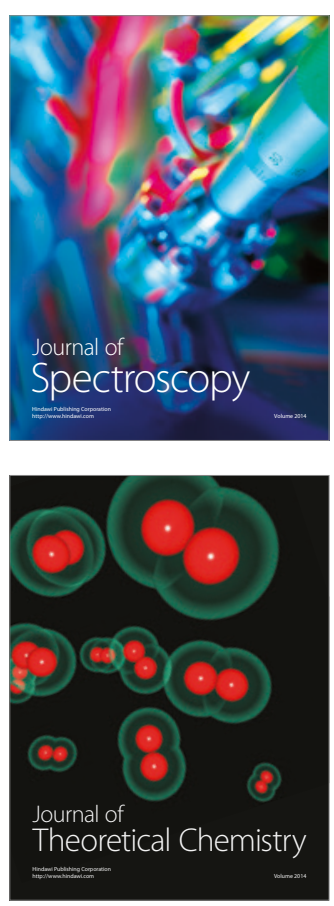
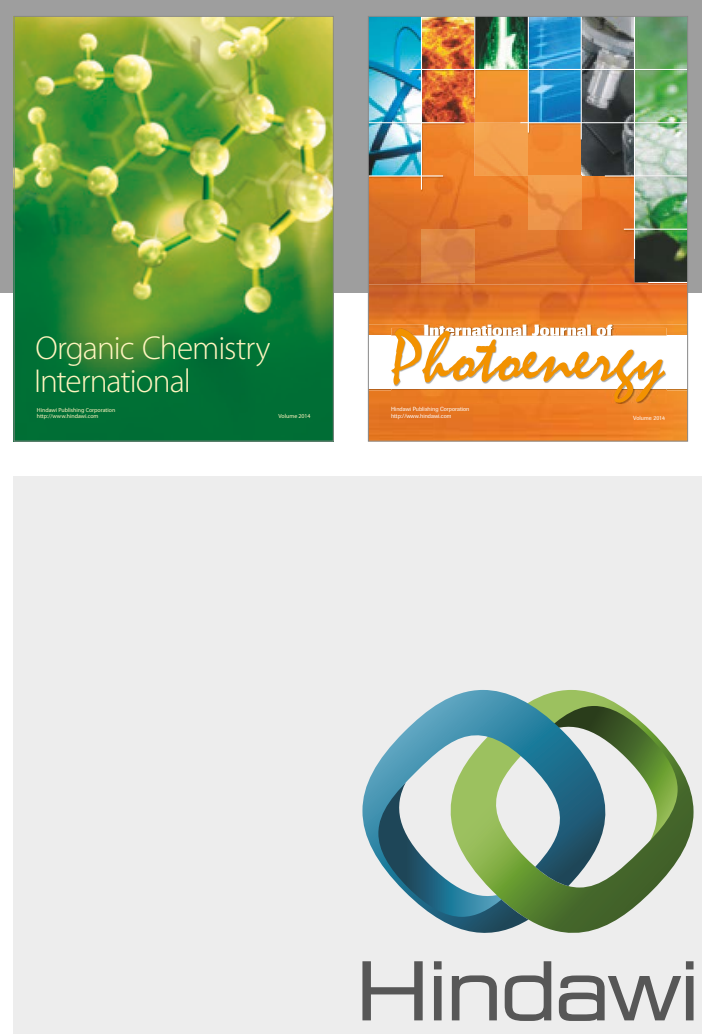

Submit your manuscripts at

https://www.hindawi.com

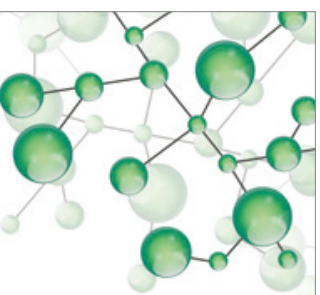

International Journal of

Inorganic Chemistry

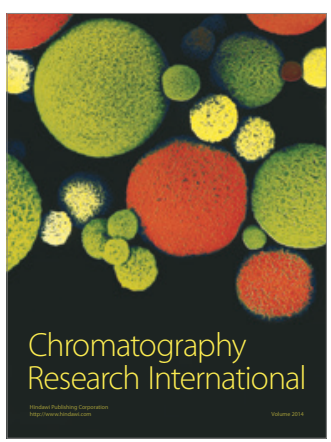

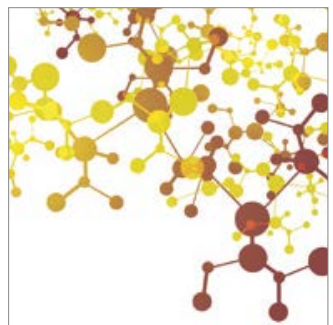

Applied Chemistry
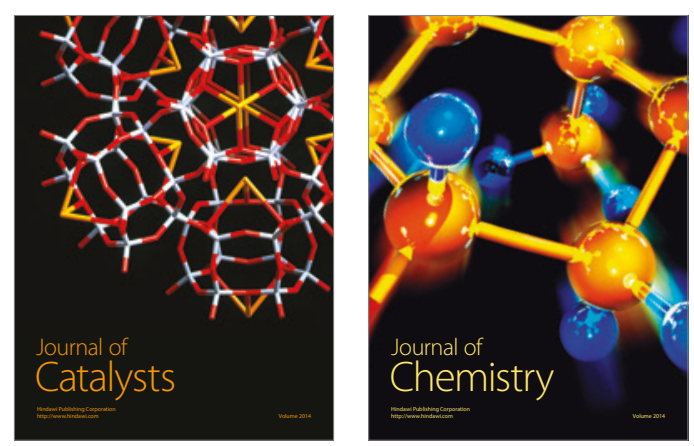
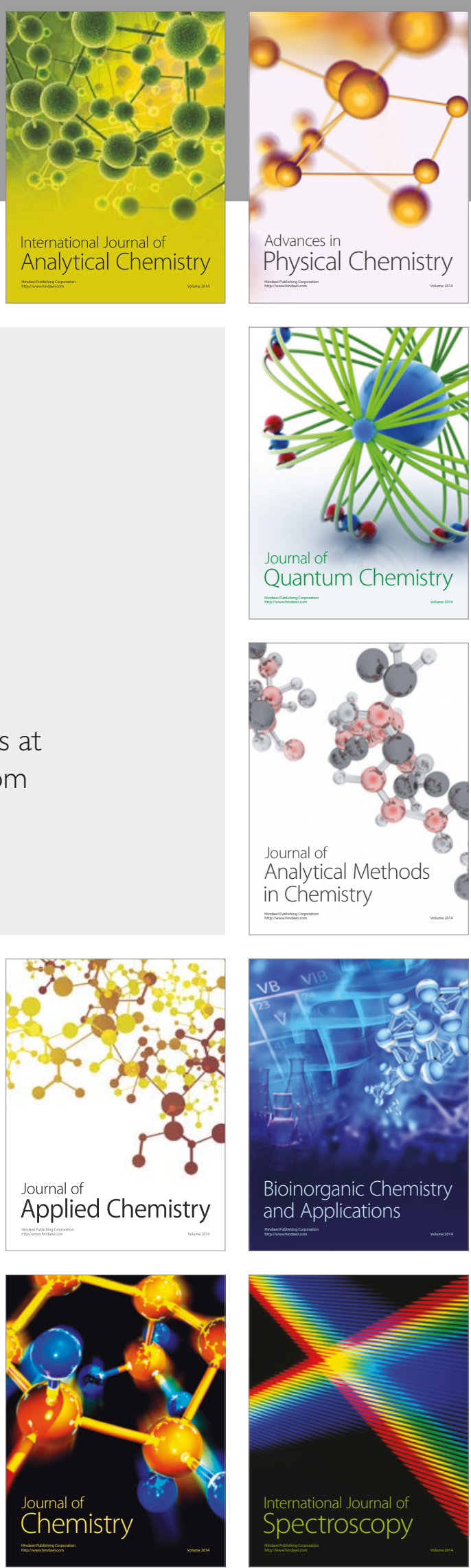